\title{
Assessment of single-dose benzodiazepines on insulin secretion, insulin sensitivity and glucose effectiveness in healthy volunteers: a double-blind, placebo-controlled, randomized cross-over trial [ISRCTN08745 I 24]
}

\author{
Hugues Chevassus ${ }^{* \dagger 1,2}$, Isabelle Mourand ${ }^{\dagger 1,2}$, Nathalie Molinier ${ }^{1}$, \\ Bruno Lacarelle ${ }^{3}$, Jean-Frédéric Brun ${ }^{4}$ and Pierre Petit ${ }^{1,2}$
}

\begin{abstract}
Address: ${ }^{1}$ Clinical Investigation Center, Saint-Eloi University Hospital, Section of Clinical Pharmacology, Montpellier, France, ${ }^{2}$ Center for Pharmacology and Health Biotechnology, CNRS UMR 5160, Montpellier, France, ${ }^{3}$ Department of Pharmacokinetics, La Timone University Hospital, Marseille, France and ${ }^{4}$ Department of Clinical Physiology, Lapeyronie University Hospital, Montpellier, France

Email: Hugues Chevassus* - h-chevassus@chu-montpellier.fr; Isabelle Mourand - cic@chu-montpellier.fr; Nathalie Molinier - cic@chumontpellier.fr; Bruno Lacarelle - Bruno.Lacarelle@mail.ap-hm.fr; Jean-Frédéric Brun - Drjfbrun@aol.com; Pierre Petit - p-petit@chumontpellier.fr

* Corresponding author †Equal contributors
\end{abstract}

Published: 04 March 2004

BMC Clinical Pharmacology 2004, 4:3

This article is available from: http://www.biomedcentral.com//472-6904/4/3

(C) 2004 Chevassus et al; licensee BioMed Central Ltd. This is an Open Access article: verbatim copying and redistribution of this article are permitted in all media for any purpose, provided this notice is preserved along with the article's original URL.
Received: 03 April 2003

Accepted: 04 March 2004

\begin{abstract}
Background: The present study aimed at investigating in healthy volunteers the effects of diazepam and clonazepam on beta-cell function, insulin sensitivity and glucose effectiveness based on the frequently sampled intravenous $\left(0.5 \mathrm{gkg}^{-1}\right)$ glucose tolerance test with minimal-model analysis.

Methods: The study was designed as a double-blind, placebo-controlled, cross-over clinical trial. Diazepam (I0 $\mathrm{mg}$ ) and clonazepam ( $\mathrm{l} \mathrm{mg}$ ) were infused during $30 \mathrm{~min}$ to 15 male subjects with a mean age of 22 years (range: 20-29), after informed consent was given. Benzodiazepines were assayed by capillary gas chromatography with electron capture, insulin by radioimmunoassay and glucose by the enzymatic glucose oxidase method.

Results: Both benzodiazepines induced significant psychotropic effects. The acute insulin responses (AIR) were significantly and negatively correlated with the clonazepam plasma concentrations $(r=-0.609, P<0.05, n=14)$. However, the mean AIR was not significantly different between the benzodiazepine-treated subjects and the controls. In addition, the parameters of glucose assimilation were significantly decreased as compared with placebo in the subgroup of 7 subjects with plasma clonazepam concentrations higher than $6.0 \mathrm{ng} \mathrm{ml}^{-1}$ (median and lower limit of effective therapeutic concentrations): $1.37 \pm 0.3$ versus $2.84 \pm 0.60 \times 10^{-2} \mathrm{~min}^{-1}(P=0.028)$ for the coefficient of glucose tolerance $\left(K_{g}\right), 2.18 \pm 0.29$ versus $3.71 \pm 0.89 \times 10^{-4} \mu \mathrm{Uml}^{-1} \mathrm{~min}^{-1}(P=0.018)$ for insulin sensitivity $\left(S_{i}\right)$ and $1.80 \pm 0.39$ versus $3.59 \pm 0.7 \mathrm{I} \times 10^{-2} \mathrm{~min}^{-1}(P=0.028)$ for glucose effectiveness at basal insulin $\left(\mathrm{S}_{\mathrm{g}}\right)$. These parameters were not significantly modified when diazepam was administered; plasma levels of this drug however, were below the effective therapeutic concentrations (300 $\left.\mathrm{ng} \mathrm{ml}^{-1}\right)$ from min 15 after the end of the perfusion.
\end{abstract}

Conclusion: The present results suggest that a benzodiazepine, in particular clonazepam, may alter insulin secretion and insulin sensitivity after a single administration in healthy volunteers. 


\section{Background}

Benzodiazepine drugs are widely prescribed, mainly for their anxiolytic and sedative properties. In addition to these psychotropic actions, different metabolic effects have also been reported but few clinical trials on that topic are available.

A trend to increased glycemia without significant modification of insulinemia was shown after a single dose administration of diazepam in healthy volunteers [1]. Aggravation of hyperglycemia has been reported during benzodiazepine treatment in diabetic patients [2]. In patients treated with the imidazopyridine compound alpidem, which binds benzodiazepine receptors [3], we reported an alteration of glucose tolerance after one week administration [4]. Studies in vitro have shown that some benzodiazepines could affect insulin secretion differently according to the experimental model $[5,6]$.

Weight gain, which is often related to insulin resistance, has also been claimed to occur in some patients treated with benzodiazepines. Different benzodiazepines have different effects on body weight gain in rats, suggesting that different subtypes of benzodiazepine receptors are involved [7].

In order to further explore the potential effects of benzodiazepines on beta-cell function and insulin sensitivity, we performed in healthy volunteers the frequently sampled intravenous glucose tolerance test with minimalmodel analysis according to Bergman et al. [8]. The singledose effects of two benzodiazepines, diazepam and clonazepam, with different affinity and selectivity for central and peripheral receptors were investigated.

\section{Methods}

Fifteen healthy male volunteers, aged $20-29$ years (mean 22.5 years), were included in this study. They underwent a full medical examination with electrocardiogram and standard biological screening before entry into the study. All subjects were in good physical condition and of normal weight (mean: $68.6 \mathrm{~kg}$; range: 55-81) and body mass index (mean: $22.3 \mathrm{~kg} / \mathrm{m}^{2}$; range: $20.1-25.0$ ). They had no previous history of significant disease and satisfied the inclusion/exclusion criteria. All volunteers gave written consent to participate after being informed of the aim of the research, its experimental protocol and potential risks. The study was approved by the institutional Ethics Committee of Montpellier and has been conducted in accordance with the Helsinki declaration and the European guideline for « Good Clinical Practice».

The study was designed as a double-blind, three-way placebo-controlled cross-over investigation of diazepam, a central and peripheral benzodiazepine receptor ligand
[9], clonazepam, a selective central receptor ligand [9], and placebo. Subjects were randomly assigned to one of the three treatment groups to control for potential order effect. The three treatments were single intravenous doses of diazepam (10 mg), clonazepam (1 mg) or placebo. The three treatment administrations were separated by a 7-day washout period.

In the morning of each test-day, subjects were admitted to the Clinical Investigation Center, in fasting conditions for at least 12 hours, namely from the evening before. The subjects remained in the supine position and a venous catheter was inserted in each forearm, one for the administration of the drugs and glucose, the other for blood sampling. The drugs in $125 \mathrm{~mL}$ saline solution or the saline solution alone (placebo) were administered during 30 min (between minutes -45 and -15). The treatments were prepared by the research nurse according to the randomization form. Fifteen minutes after the end of the perfusion, the frequently sampled intravenous glucose tolerance test (FSIVGTT) was started, with a glucose load of $0.5 \mathrm{~g} / \mathrm{kg}$ in $3 \mathrm{~min}$ and a bolus of $0.03 \mathrm{U} / \mathrm{kg}$ insulin just before minute 20. Blood samples were taken at times -45 , -15 and 0 , then at $1,3,4,6,8,10,15,19,20,22,24,30$, $41,70,90$ and 180 minutes after glucose injection for the measurement of plasma glucose and serum insulin concentrations. Additional samples were taken at times -45, 15,0 , then at $15,30,60,120$ and 180 minutes after glucose injection for the measurement of plasma diazepam, $\mathrm{N}$-desmethyldiazepam, clonazepam and cortisol.

Furthermore, the subjects' mood and feelings were selfrated before (time $-45 \mathrm{~min}$ ) and after the infusion (time $15 \mathrm{~min}$ ), and then at times 70 and 180 minutes, using the 49-item questionnaire from the Addiction Research Center Inventory (ARCI) and the Norris series of 16 bipolar visual analogue scales (VAS). At the end of the test day, subjects were discharged after a last clinical evaluation.

After immediate centrifugation of the blood samples $(1500 \mathrm{~g}, 10 \mathrm{~min})$, plasma or serum was separated and frozen at $-20^{\circ} \mathrm{C}$. Plasma glucose levels were assayed by the glucose oxidase method derived from Trinder [10]. Serum insulin and plasma cortisol were measured by radioimmunoassay using the marketed immunoradiometric kit INSIK-5 purchased from DiaSorin (Saluggia, Italy). Diazepam, N-desmethyldiazepam and clonazepam were assayed by a capillary gas chromatography technique with electron capture, adapted from a previously published method [11]. Briefly, benzodiazepines were extracted from plasma at $\mathrm{pH}=9.0$ by ethyl ether. GLC analysis was performed on a HP-5 (crosslinked $5 \% \mathrm{PH}$ ME siloxane) $30 \mathrm{~m} \times 0.32 \mathrm{~mm} \times 0.25 \mu \mathrm{m}$ capillary column (Agilent) at an oven temperature from 170 to $250^{\circ} \mathrm{C}$ $\left(2^{\circ} \mathrm{C} / \mathrm{min}\right)$. The intra and inter-assay variability ranged 
from $4.7 \%$ to $9.9 \%$ for clonazepam, $2.7 \%$ to $7.4 \%$ for diazepam and $5.4 \%$ to $9.7 \%$ for N-desmethyldiazepam for three quality control concentrations.

Acute insulin response (AIR) was used as an index of the first-phase insulin secretion and was calculated as the mean of the serum insulin concentrations at times 1, 3, 4, 6,8 and 10 minutes.

The least-square slope of the log of the absolute glucose concentration between 4 and 19 minutes after the glucose bolus was used as an index of glucose tolerance $\left(\mathrm{K}_{\mathrm{g}}\right)$.

Minimal-model analysis of the FSIVGTT was performed according to the method previously reported by Bergman et al. [8] and Yang et al. [12], using the software TISPAG from the Department of Clinical Physiology, Lapeyronie University Hospital, (Montpellier, France), which uses a nonlinear least-square estimation [13]. This program produced the values for insulin sensitivity $\left(\mathrm{S}_{\mathrm{i}}\right)$ and glucose effectiveness $\left(S_{g}\right)$. $S_{i}$ and $S_{g}$ are calculated from the equations $\mathrm{dG}(\mathrm{t}) / \mathrm{dt}=-[\mathrm{p} 1+\mathrm{X}(\mathrm{t})] \mathrm{G}(\mathrm{t})+\mathrm{p} 1 \mathrm{~Gb}, \mathrm{G}(0)=\mathrm{Go}$, $\mathrm{dX}(\mathrm{t}) / \mathrm{dt}=-\mathrm{p} 2 \mathrm{X}(\mathrm{t})+\mathrm{p} 3[\mathrm{I}(\mathrm{t})-\mathrm{Ib}]$, and $\mathrm{X}(0)=0$, where $\mathrm{G}(\mathrm{t})$ and $\mathrm{I}(\mathrm{t})$ are plasma glucose and insulin concentrations, $\mathrm{X}(\mathrm{t})$ is the insulin in a compartment remote from plasma (insulin action), and p1 to $\mathrm{p} 3$ are model parameters. Go is the glucose concentration that would be obtained immediately after injection if there was instantaneous mixing in the extracellular fluid compartment. Gb and Ib are basal values of glucose and insulin. Parameter $\mathrm{p} 1$ represents $S_{g^{\prime}}$ i.e. the fractional disappearance rate of glucose independent of any insulin response, and p3 and p2 determine the kinetics of insulin transport, respectively, into and out the remote insulin compartment where insulin action is expressed. $S_{i}$ is an index of the influence of plasma insulin to change the glucose effect per se on glucose concentration. Thus, $S_{\mathrm{i}}$ is equal to $-\mathrm{p} 3 / \mathrm{p} 2$.

$\mathrm{S}_{\mathrm{g}}$ was divided into its two components: the contribution of hyperglycemia per se to tissue glucose utilization and the effect of basal insulin on glucose uptake. The basal insulin component of $S_{g}$ is BIE and can be calculated as the product of basal insulin Ib and $\mathrm{S}_{\mathrm{i}}$ : $\mathrm{BIE}=\mathrm{Ib} \times \mathrm{S}_{\mathrm{i}}$. Thus, the contribution of non-insulin-dependent glucose uptake (GEZI) to glucose uptake is the difference between total $S_{\mathrm{g}}$ and the BIE: GEZI $=\mathrm{S}_{\mathrm{g}}-\left(\mathrm{Ib} \times \mathrm{S}_{\mathrm{i}}\right)$.

The sample size was calculated from clinical data on AIR obtained in a control sample after FSIVGTT, with the 2sided hypothesis of a difference between diazepam and placebo or clonazepam and placebo of at least 35\%; the study power was set at $90 \%$ and the significance threshold at $5 \%$. All the results are given as means \pm standard error (s.e. mean). Where necessary, 95\% confidence intervals on differences $(95 \% \mathrm{CI})$ are given. The time courses of mean cortisol concentrations were compared using repeated measures ANOVA. Other kinetics data were integrated in areas under the curves (AUC), calculated including baseline by the trapezoidal rule using the Systat ${ }^{\boxplus} 6.0$ software for Windows ${ }^{\circledast}$. AUC means were compared using the nonparametric Friedman test for related data. Spearman correlations were performed between AIR and diazepam or clonazepam concentrations. Post hoc and subgroups analysis were performed where necessary using the paired $t$-test for cortisol and the Wilcoxon rank-sum test for other paired data. The Systat ${ }^{\circledast} 6.0$ software for Windows ${ }^{\varpi}$ was also used for the statistical analysis.

\section{Results}

Intravenous administration of $10 \mathrm{mg}$ diazepam during 30 min yielded to plasma concentrations peaking at $370.1 \pm$ $22.6 \mathrm{ngml}^{-1}$ at time $-15 \mathrm{~min}$, just at the end of the infusion. The concentrations rapidly decreased to $229.7 \pm 12.6$ ngml $^{-1}$ at time 0 , before glucose administration (Figure 1 , A). The mean concentrations of $\mathrm{N}$-desmethyldiazepam ranged between $3.2 \pm 0.9 \mathrm{ngml}^{-1}$ at $\min -15$ and $9.1 \pm 1.6$ $\mathrm{ngml}^{-1}$ at min 180 . Intravenous infusion of $1 \mathrm{mg}$ clonazepam over $30 \mathrm{~min}$ led to a mean maximal concentration of $15.1 \pm 2.0 \mathrm{ngml}^{-1}$ at min -15 (Figure 1, B); the mean concentrations at times 0 and 15 minutes were 6.6 \pm 0.5 and $4.9 \pm 0.4 \mathrm{ngml}^{-1}$, respectively.

Concerning the psychotropic effects of the drugs, the pentobarbital-chlorpromazine-alcohol group (PCAG) scores of the ARCI, which reflect sedation, were significantly different with treatment $(\mathrm{P}<0.001$, Figure 2$)$; a significant increase was observed for diazepam $(+363 \% v s$ placebo, 95\% CI: 214.0, 820.7, $\mathrm{n}=15, \mathrm{P}=0.004)$ and clonazepam (+593\% vs placebo, 95\% CI: 511.2, 1146.3, $\mathrm{n}$ $=14, \mathrm{P}=0.001)$. The benzedrine group $(\mathrm{BG})$ scores, which explore stimulation, were also significantly different with treatment $(\mathrm{P}<0.017$, Figure 2$)$; a significant decrease was observed for clonazepam $(-153 \%$ vs placebo, 95\% CI: $-598.2,-170.3, \mathrm{n}=14, \mathrm{P}=0.004)$. Concerning the other factors of the ARCI, the scores of the morphinebenzedrine group (MBG), assessing euphoria, of the LSD group, assessing dysphoric and psychotomimetic changes, and of the amphetamine group, assessing amphetaminelike effects were not significantly modified with treatment (not shown). On the VAS, the self-rating of astheniafatigue (factor 1) scores were also significantly modified with treatment $(P=0.002)$, with a similar time-course as the PCAG score of the ARCI (not shown); a significant increase was observed for diazepam $(+42.3 \%$ vs placebo, $95 \%$ CI: 899.1, 4501.6, $\mathrm{n}=15, \mathrm{P}=0.015)$ and clonazepam $(+70.3 \%$ vs placebo, $95 \%$ CI: $2402.2,6516.4, \mathrm{n}=$ $14, \mathrm{P}=0.002)$.

In addition, there was a significant difference $(\mathrm{P}=0.028)$ in the time course of plasma cortisol concentrations 
A

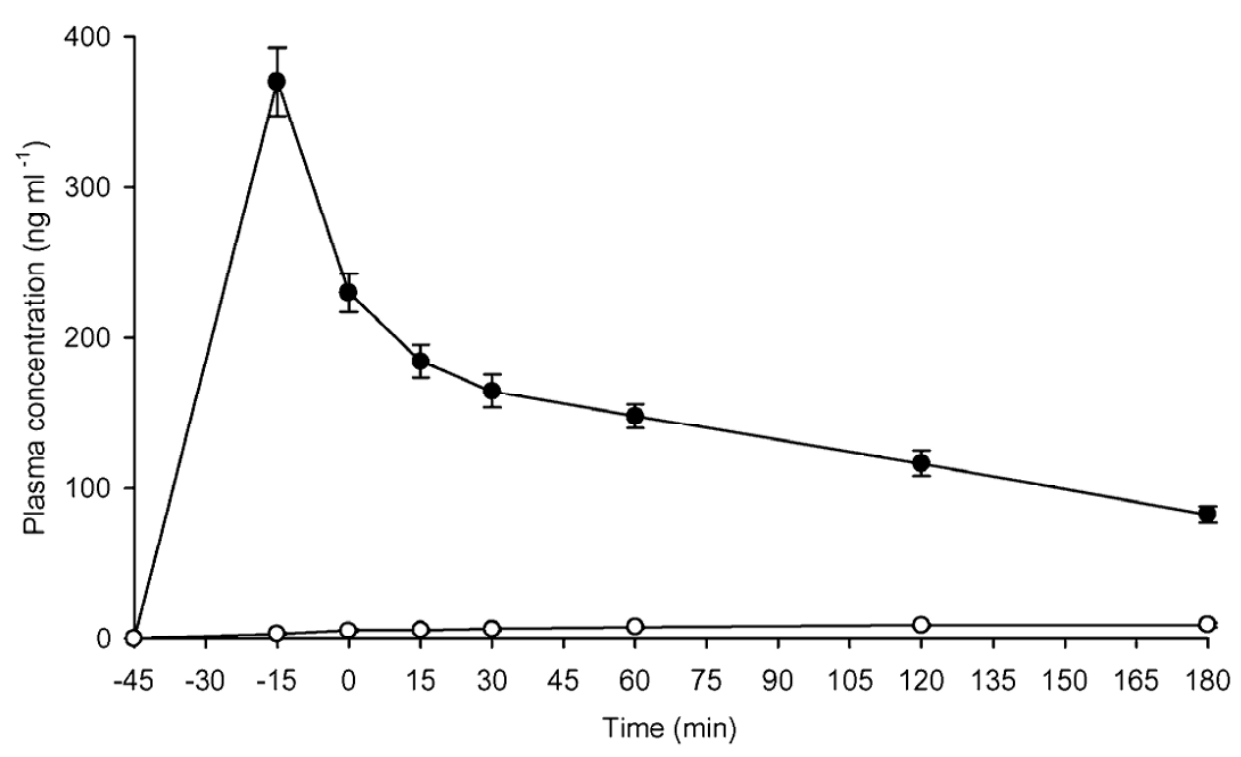

B

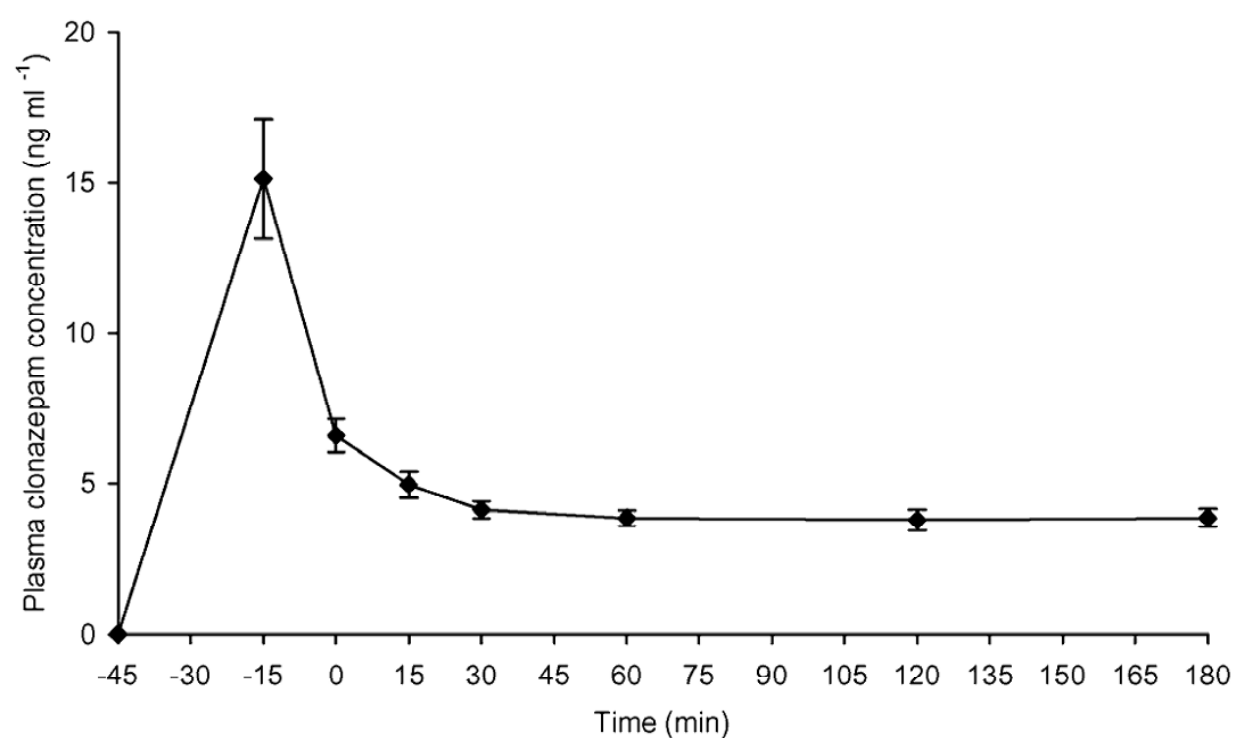

Figure I

Plasma concentrations after diazepam and clonazepam infusion. A Time course of plasma diazepam and $\mathrm{N}$-desmethyldiazepam concentrations after $10 \mathrm{mg}$ diazepam infusion (during $30 \mathrm{~min}$ from time $-45 \mathrm{~min}$ to time $-15 \mathrm{~min}$ ) during FSIVGTT $(0.5 \mathrm{~g} / \mathrm{kg}$ glucose load at time $0 \mathrm{~min}$ ). diazepam; $\bigcirc \mathrm{N}$-desmethyldiazepam. B Time course of plasma clonazepam concentration after I mg clonazepam infusion (during $30 \mathrm{~min}$ from time $-45 \mathrm{~min}$ to time $-15 \mathrm{~min}$ ) during FSIVGTT ( $0.5 \mathrm{~g} / \mathrm{kg}$ glucose load at time $0 \mathrm{~min}$ ). clonazepam. 


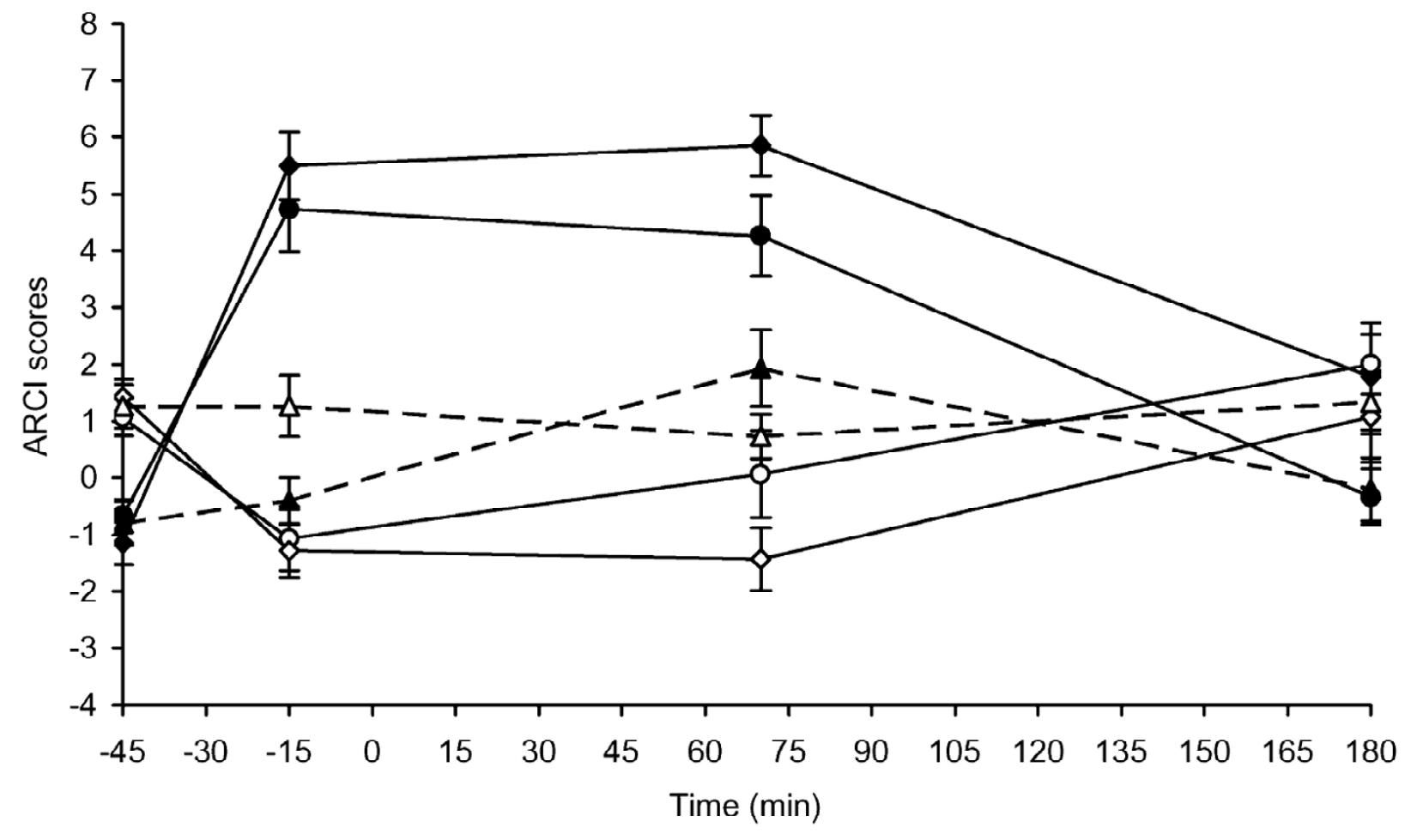

\section{Figure 2}

Time course of PCAG- and BG-scores of the ARCl after $10 \mathrm{mg}$ diazepam, I $\mathrm{mg}$ clonazepam or placebo infusion (during 30 min from time $-45 \mathrm{~min}$ to time - $15 \mathrm{~min})$ during FSIVGTT $(0.5 \mathrm{~g} / \mathrm{kg}$ glucose load at time $0 \mathrm{~min})$. PCAG scores after diazepam infusion; $\diamond$ PCAG scores after clonazepam infusion; $\triangle$ PCAG scores after placebo infusion; $O B G$ scores after diazepam infusion; $\diamond B G$ scores after clonazepam infusion; $\triangle B G$ scores after placebo infusion.

between the different groups (Figure 3); a significant reduction was observed at time $60 \mathrm{~min}$ for diazepam ($33.3 \%$ vs placebo, 95\% CI: $-130.4,-38.3, \mathrm{n}=15, \mathrm{P}=$ $0.002)$ and clonazepam (-24.0\% vs placebo, 95\% CI: $119.0,-2.6, \mathrm{n}=15, \mathrm{P}=0.042)$.

As shown in figure 4, the acute insulin responses (AIR) were significantly and negatively correlated with the plasma concentrations of clonazepam $(\mathrm{r}=-0.609, \mathrm{P}<$ $0.05, \mathrm{n}=14$ ) at time 0 minute, just before glucose injection. However, the mean AIR were not significantly different between the benzodiazepine-treated subjects and the controls (Table 1).
Overall, glucose tolerance, insulin sensitivity and glucose effectiveness were not significantly different between the benzodiazepine-treated subjects and the controls (Table $1)$. However, as shown in figure 5, a concentrationdependent effect could be observed with clonazepam. Indeed, in the subgroup of 7 subjects with plasma clonazepam concentrations at time 0 minute higher than 6.0 ngml $^{-1}$ (median and lower limit of effective therapeutic concentrations), each of these parameters was significantly decreased as compared with placebo: $-51.8 \%(95 \%$ CI: $\left.-2.58,-0.37 \times 10^{-2} \mathrm{~min}^{-1}, \mathrm{P}=0.028\right)$ for the coefficient of glucose tolerance $\left(\mathrm{K}_{\mathrm{g}}\right),-41.2 \%(95 \% \mathrm{CI}:-3.04,-0.02 \times$ $\left.10^{-4} \mu \mathrm{Uml}^{-1} \mathrm{~min}^{-1}, \mathrm{P}=0.018\right)$ for insulin sensitivity $\left(\mathrm{S}_{\mathrm{i}}\right)$ and $-49.9 \%$ (95\% CI: $\left.-3.07,-0.51 \times 10^{-2} \mathrm{~min}^{-1}, \mathrm{P}=0.028\right)$ for glucose effectiveness at basal insulin $\left(\mathrm{S}_{\mathrm{g}}\right)$. 


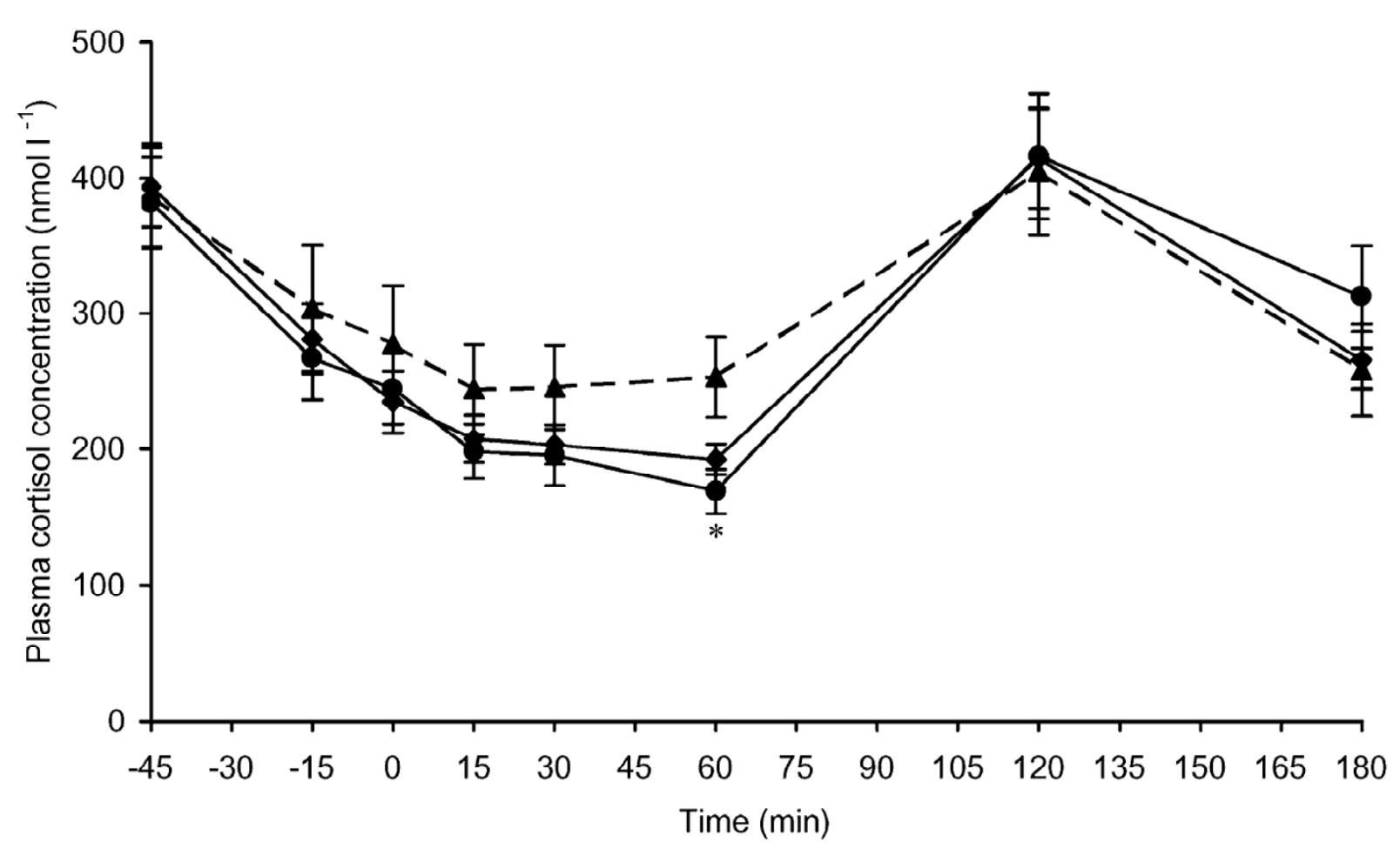

Figure 3

Time course of plasma cortisol after $10 \mathrm{mg}$ diazepam, I mg clonazepam or placebo infusion (during $30 \mathrm{~min}$ from time $-45 \mathrm{~min}$ to time $-15 \mathrm{~min})$ during FSIVGTT $(0.5 \mathrm{~g} / \mathrm{kg}$ glucose load at time $0 \mathrm{~min})$. diazepam; $\bullet$ clonazepam; $\boldsymbol{\Delta}$ placebo; $* \mathrm{P}<0.05 \mathrm{for}$ diazepam vs placebo and clonazepam vs placebo.

Furthermore, the two components of $\mathrm{S}_{\mathrm{g}}$ were significantly decreased with clonazepam $v$ s placebo in the subgroup of subjects with the highest plasma clonazepam concentrations at time 0 minute: $-38.1 \%\left(95 \% \mathrm{CI}:-0.18,-0.03 \times 10^{-}\right.$ ${ }^{2} \mathrm{~min}^{-1}, \mathrm{P}=0.018$ ) for basal insulin effctiveness (BIE) and $-50.9 \%$ (95\% CI: $\left.-2.97,-0.40 \times 10^{-2} \mathrm{~min}^{-1}, \mathrm{P}=0.028\right)$ for glucose effectiveness at zero insulin (GEZI).

\section{Discussion}

The present study investigated the effects of a single-dose administration of different benzodiazepines on $\beta$-cell function and insulin sensitivity in healthy volunteers.

Intravenous administration of $10 \mathrm{mg}$ diazepam or $1 \mathrm{mg}$ clonazepam led to peak concentrations at the end of the infusion within the standard effective plasma concentra- tions of these drugs, namely 300-400 ngml-1 for $^{-1}$ diazepam and 5-70 $\mathrm{ngml}^{-1}$ for clonazepam [14]. However, whereas the plasma levels of diazepam rapidely decreased below the standard effective concentrations, the mean concentrations of clonazepam further remained around the lower limit of effective concentrations.

Both diazepam and clonazepam induced significant psychological effects, as judged by the PCAG and BG scores of the ARCI and the asthenia-fatigue factor of the VAS, which is in accordance with previously reported data on the subjective effects induced by benzodiazepines [15]. These effects were still significant at time 70 minutes, ie approximately one and a half hour after the end of the infusion, although at that time, the PCAG and VAS factor 1 scores were also increased in the placebo group. This latter 


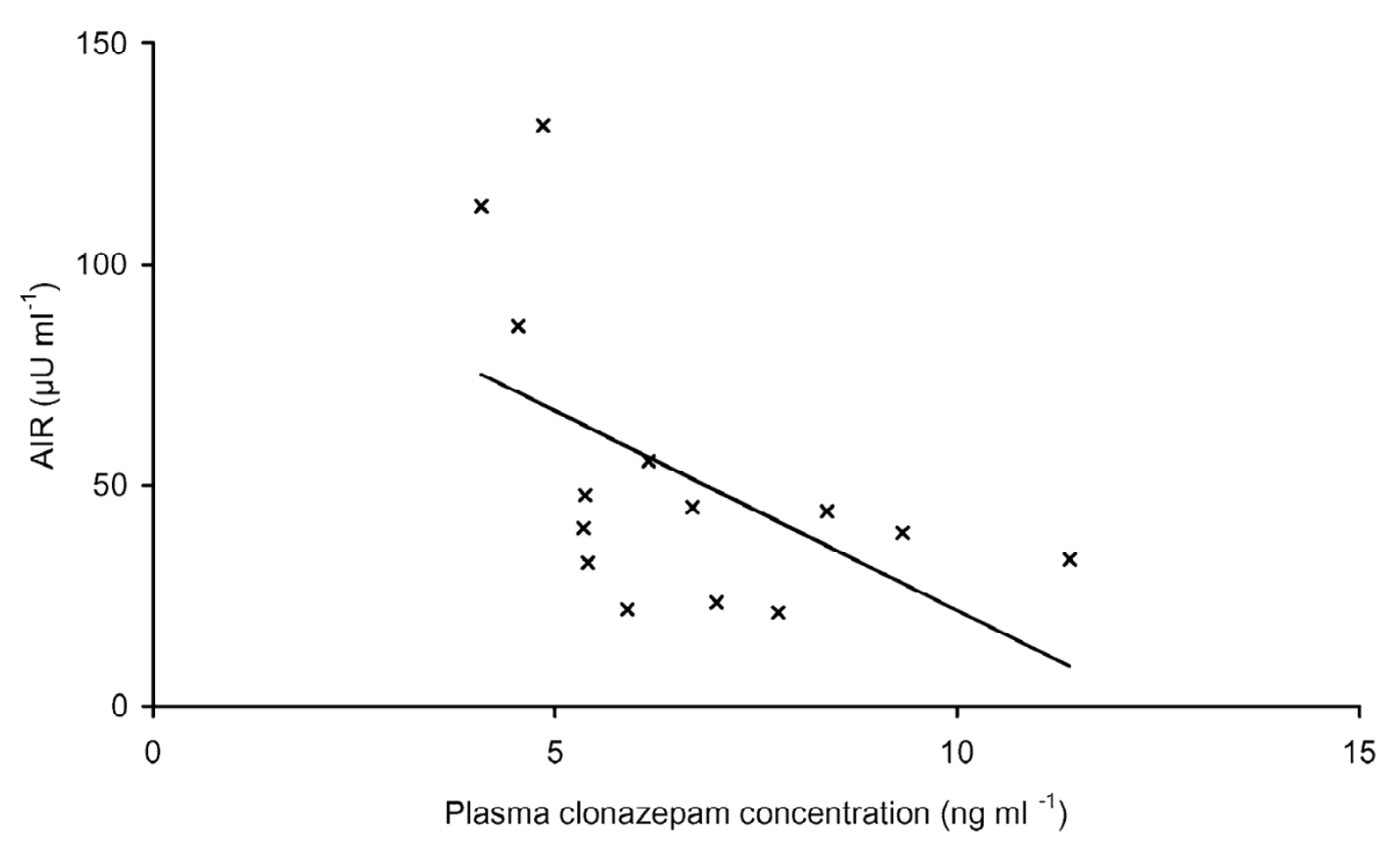

\section{Figure 4}

Correlation of acute insulin response (AIR), calculated from serum insulin concentrations obtained during the 10 first minutes after glucose injection, with the plasma concentrations of clonazepam obtained at time 0 min, just before glucose injection ( $r$ ' = $-0.609, P<0.05, n=14)$.

Table I: Values of the parameters of insulin secretion, glucose tolerance, insulin sensitivity and glucose effectiveness according to the different treatment-groups.

\begin{tabular}{lllll}
\hline Treatment & AIR $\left(\mu \cup \mathrm{ml}^{-1}\right)$ & $\mathrm{K}_{\mathrm{g}}\left(\times 10^{-2} \mathrm{~min}^{-1}\right)$ & $\mathrm{S}_{\mathrm{i}}\left(\times 10^{-4} \mu \cup \mathrm{ml}^{-1} \mathrm{~min}^{-1}\right)$ & $\mathrm{S}_{\mathrm{g}}\left(\times 10^{-2} \mathrm{~min}^{-1}\right)$ \\
\hline Diazepam & $52.9 \pm 13.7$ & $2.27 \pm 0.26$ & $3.52 \pm 0.52$ & $2.98 \pm 0.30$ \\
Clonazepam & $51.2 \pm 8.6$ & $1.78 \pm 0.37$ & $3.70 \pm 0.79$ & $2.39 \pm 0.48$ \\
Placebo & $53.9 \pm 10.7$ & $2.65 \pm 0.31$ & $3.50 \pm 0.47$ & $3.42 \pm 0.37$ \\
\hline
\end{tabular}

observation may be the result of the hypoglycemia measured at that time $\left(2.4 \pm 0.1 \mathrm{mmoll}^{-1}\right)$ and resulting from the insulin bolus, since acute hypoglycemia has been reported to affect brain function and activation [16]. On the other hand, the treatment by either benzodiazepine also induced a significant biological effect on plasma cortisol concentrations, which were decreased in the benzodiazepine-treated groups as compared with controls. This result is in accordance with previous studies in the literature $[17,18]$, although not all studies have reported that a 
A

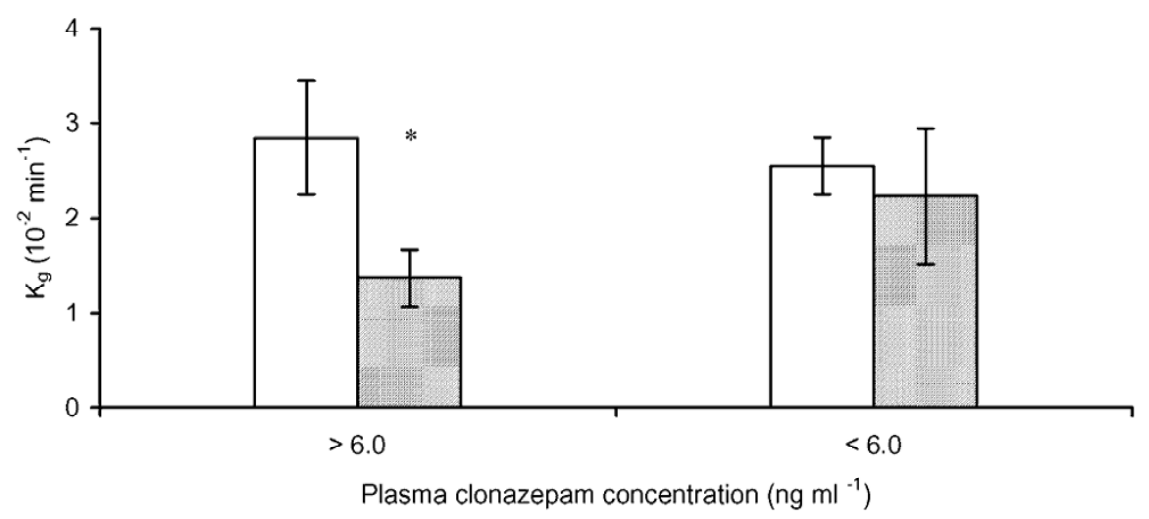

B

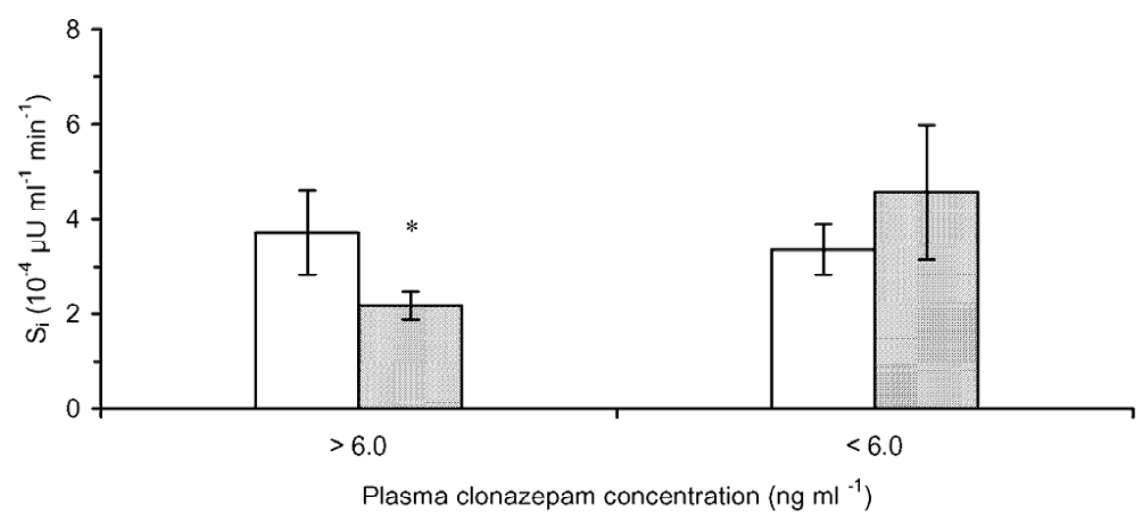

C

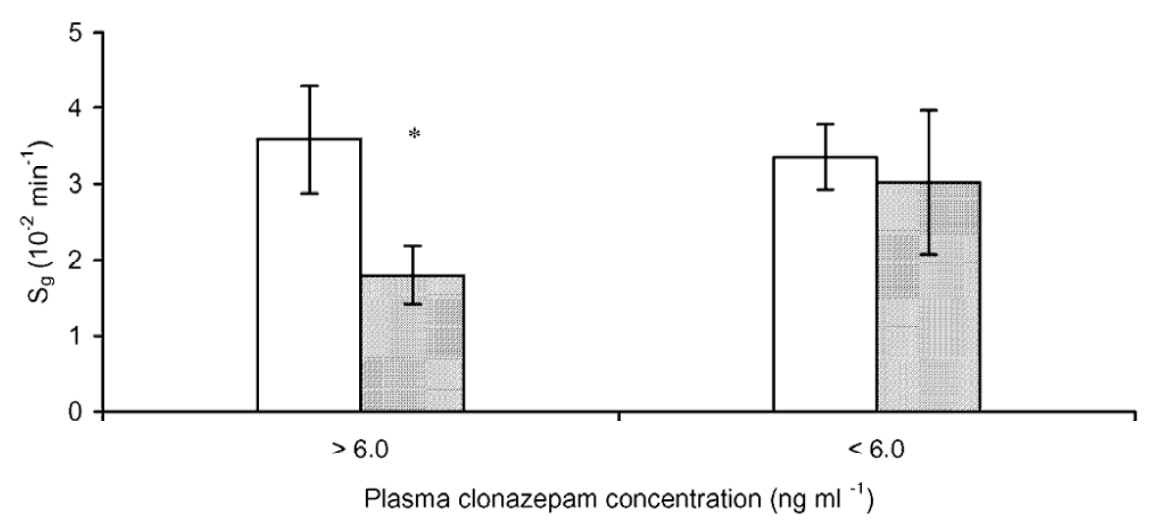

\section{Figure 5}

Effects of clonazepam on glucose tolerance, insulin sensitivity and glucose effectiveness. A Effect of clonazepam on glucose tolerance $\left(\mathrm{K}_{\mathrm{g}}\right)$ according to plasma clonazepam concentration. White bars, controls; Striped bars, treated; $* \mathrm{P}<0.05$ vs placebo. B Effect of clonazepam on insulin sensitivity $\left(\mathrm{S}_{\mathrm{i}}\right)$ according to plasma clonazepam concentration. White bars, controls; Striped bars, treated; * $\mathrm{P}<0.05$ vs placebo. C Effect of clonazepam on glucose effectiveness at basal insulin $\left(\mathrm{S}_{\mathrm{g}}\right)$ according to plasma clonazepam concentration. White bars, controls; Striped bars, treated; * $\mathrm{P}<0.05$ vs placebo. 
single dose of benzodiazepine affects cortisol secretion in healthy volunteers [19]. This effect of benzodiazepines on cortisol is in agreement with the inhibiting action of gabaergic agonists on the corticotropin releasing hormone secretion, as observed in vitro in rats [20]. It can also be observed that there is a relative increase in plasma cortisol concentrations following the lowest glucose concentrations (at time 70 minute), and that this cortisol response to insulin-induced hypoglycemia is not affected by either benzodiazepine, in accordance with some [21] but not all previously reported data [22].

Considering the metabolic effects, the present study shows that clonazepam is able to reduce the acute insulin response to a glucose challenge in healthy volunteers, in a concentration-dependent manner. This result is in accordance with previously reported data showing that Diazepam Binding Inhibitor (DBI), which is an endogenous ligand for both central and peripheral benzodiazepine receptors, dose-dependently inhibited glucoseinduced insulin secretion in vitro in rat isolated islets $[23,24]$. In the same way, it supports previous observations that benzodiazepines or related compounds alter glucose tolerance in vivo in the rat [25] or in patients [4]. Other experiments however have shown in vitro that drugs acting specifically at peripheral benzodiazepine receptors inhibit glucose-induced insulin secretion [5] by reducing oxidative metabolism [26], whereas clonazepam, which binds very weakly to peripheral sites [27], is ineffective [5]. The peripheral-type receptor agonist, 4'-chlordiazepam, was also reported to increase glycaemia after intraperitoneal administration in the mice [28]. These discrepant data concerning clonazepam may be due to species variations or the result of an indirect central effect of the drug in our study. At the concentrations obtained with the single dose administered, there was no overall effect of clonazepam on the acute insulin response according to the different groups. Diazepam was ineffective as well, which may be the result of too low plasma concentrations over time. It is noteworthy to observe that both drugs however have significant psychotropic effects as well as effects on cortisol, even after $75 \mathrm{~min}$ after the end of the infusion, suggesting differential potencies relative to these effects.

On the other hand, this study shows for the first time that a benzodiazepine can reduce both insulin sensitivity ( $\mathrm{Si}$ ) and non-insulin-mediated glucose disposal (Sg and its components), provided that its concentration is above the admitted therapeutic threshold. Apart from the peak concentrations, this was especially the case for clonazepam but not for diazepam. There is no clear explanation for that observation. However, since insulin sensitivity and non-insulin mediated glucose disposal have been shown to increase even shortly after muscular activity [13], it can be tentatively speculated that the wellknown muscle relaxant action of the benzodiazepine may alter insulin sensitivity and glucose disposal.

\section{Conclusions}

Even if clinical metabolic events related to benzodiazepines are uncommon, the results of the present study on both insulin secretion and insulin action prompt to suggest that, on the long term, these drugs may be a potential risk factor for glycemic dysregulation.

\section{Competing interests}

None declared.

\section{Author's contributions}

HC participated in the design of the study, managed the research, writed the standard operating procedures, handled data, conducted statistical analyses and participated in drafting the manuscript. IM collected informed consents, supervised selection procedures and clinical investigations, reported verified data on the CRF. NM participated in clinical tasks described above. BL carried out benzodiazepines assays. JFB computed glucose tolerance, insulin secretion and insulin sentivity indexes. PP conceived of the study and coordinated the data analysis and the draft writing. All authors read and approved the final manuscript.

\section{Acknowledgements}

The authors thank A. Bonardet (Department of Biochemistry), B. BoriesAzeau (Clinical Investigation Center), N. Bressot (Department of Nuclear Medicine), F. Costa (Clinical Investigation Center), M. Giocanti (Department of Pharmacokinetics), M.C. Picot (Department of Medical Information) and A.M. Puech-Cathala (Department of Nuclear Medicine) for expert technical and logistic assistance.

This study was supported by a grant from the French Drug Agency (AFSSAPS) and promoted by the University Hospital of Montpellier ( $\left.n^{\circ} 7546\right)$.

\section{References}

I. Syvälahti EKG, Kanto JH: Serum growth hormone, serum immunoreactive insulin and blood glucose response to oral and intravenous diazepam in man. Int J Clin Pharmacol 1975, I 2:74-82.

2. Zumoff B, Hellman L: Aggravation of diabetic hyperglycemia by chlordiazepoxide. JAMA 1977, 237:1960-1961.

3. Langer SZ, Arbilla S: Imidazopyridines as a tool for the characterization of benzodiazepine receptors. Pharmacol Biochem Behav 1988, 29:763-766.

4. Bottaï T, Cartault F, Pouget R, Blayac JP, Petit P: An imidazopyridine anxiolytic alters glucose tolerance in patients: a pilot investigation. Clin Neuropharmacol 1995, 18:79-82.

5. Petit $P$, Manteghetti $M$, Berdeu $D$, Ribes $G$, Loubatières-Mariani $M M$ : Effects of a peripheral-type benzodiazepine on glucoseinduced insulin secretion. European J Pharmacol 1992, 221:359-363.

6. Marchetti P, Trincavelli L, Giannarelli R, Giusti L, Coppelli A, Martini $C$, Navalesi R, Lucacchini A: Characterization of peripheral benzodiazepine receptors in purified large mammal pancreatic islets. Biochem Pharmacol 1996, 5 I: I 437- I 442.

7. Jing $X$, Wala EP, Sloan JW: The effects of chronic benzodiazepines exposure on body weight in rats. Pharmacol Res 1998, 37:179-189. 
8. Bergman RN, Ider $Y Z$, Bowden CR, Cobelli C: Quantitative estimation of insulin sensitivity. Am J Physiol 1979, 236:E667-E677.

9. Wang JKT, Taniguchi T, Spector S: Structural requirements for the binding of benzodiazepines to their peripheral-type sites. Mol Pharmacol 1984, 25:349-35I.

10. Trinder P: Determination of blood glucose using an oxidaseperoxydase system with a non-carcinogenic chromogen. J Clin Pathol 1969, 22: I58-161.

II. Crevat-Pisano P, Drouet C, Lacarelle B, Alazia M, Francois G, Cano JP: Validation of a radioreceptor assay technique for monitoring pharmacological active material during intensive diazepam tetanus therapy. Int J Clin Pharmacol Ther Toxicol 1987, 25:366-373.

12. Yang YJ, Youn JA, Bergman RN: Modified protocols to improve insulin sensitivity estimation using the minimal model. $\mathrm{Am}$ Physiol 1987, 253:E595-E602.

13. Brun JF, Guintrand-Hugret R, Boegner C, Bouix O, Orsetti A: Influence of short-term submaximal exercise on parameters of glucose assimilation analysed with the minimal model. Metabolism 1995, 44:833-840.

14. Gilman AG: In: The Pharmacological Basis of Therapeutics Edited by: Hardman JG, Limbird LE. New York, McGraw-Hill; 1996: I73I- 1734.

15. De Wit H, Griffiths RR: Testing the abuse liability of anxiolytic and hypnotic drugs in humans. Drug and Alcohol Dependence 1991, 28:83-III.

16. Rosenthal JM, Amiel SA, Yágüez L, Bullmore E, Hopkins D, Evans M, Pernet A, Reid H, Giampietro V, Andrew CM et al:: The effect of acute hypoglycemia on brain function and activation. A functional magnetic resonance imaging study. Diabetes 200I, 50:1618-1626.

17. Gram LF, Christensen L, Kristensen CB, Kragh-Sorensen P: Suppression of plasma cortisol after oral administration of oxazepam in man. Br J Clin Pharmacol 1984, 17:176-178.

18. Roy-Byrne PP, Cowley DS, Hommer D, Ritchie J, Greenblatt D, Nemeroff C: Neuroendocrine effects of diazepam in panic and generalized anxiety disorders. Biol Psychiatry 1991, 30:73-80.

19. Breier A, Charney DS, Heninger GR: Intravenous diazepam fails to change growth hormone and cortisol secretion in humans. Psychiatry Res 1986, 18:293-299.

20. Calogero AE, Gallucci WT, Chrousos GP, Gold PW: Interaction between gabaergic neurotransmission and rat hypothalamic corticotropin releasing hormone secretion in vitro. Brain Res 1988, 463:28-36.

21. Ambrosi F, Ricci S, Quartesan R, Moretti P, Pelicci G, Pagliacci C, Nicoletti l: Effects of acute benzodiazepine administration on growth hormone, prolactin and cortisol release after moderate insulin-induced hypoglycemia in normal women. Psychopharmacology 1986, 88: 187-189.

22. Petraglia F, Baralakis S, Fachinetti F, Volpe A, Muller EE, Genazzani AR: Effects of sodium valproate and diazepam on betaendorphin, beta-lipotropin and cortisol secretion induced by hypoglycemia stress in humans. Neuroendocrinology 1986, 44:320-325.

23. Östenson CG, Ahrén B, Karlsson S, Sandberg E, Efendic S: Effects of porcine diazepam-binding inhibitor on insulin and glucagon secretion in vitro from the rat endocrine pancreas. Regulatory Peptides 1990, 29:143-15I.

24. Östenson CG, Ahrén B, Johansson O, Karlsson S, Hilliges M, Efendic $S$ : Diazepam binding inhibitor and the endocrine pancreas. Neuropharmacology 1991, 30:1391-1398.

25. Seyer-Hansen K: The effects of diazepam on glucose tolerance in rats. Diabetologia 1972, 8:66-67.

26. Pujalte D, Claeysen S, Dietz S, Chapal J, Hillaire-Buys D, Petit P: Inhibition of glucose-induced insulin secretion by a peripheraltype benzodiazepine receptor ligand (PKIII95). NaunynSchmiedeberg's Arch Pharmacol 2000, 362:46-5I.

27. Braestrup C, Squires R: Specific benzodiazepine receptors in rat brain characterized by high-affinity $\left[{ }^{3} \mathrm{H}\right]$ diazepam binding. Proc Natl Acad Sci USA I 977, 74:3805-3809.

28. Najim RA, Al-Essa LY, Al-jibouri LM: Effect of some drugs acting at the peripheral-type benzodiazepine receptors on blood glucose in mice. Med Sci Res 1989, 17:783-784.

\section{Pre-publication history}

The pre-publication history for this paper can be accessed here:

http://www.biomedcentral.com/1472-6904/4/3/prepub
Publish with Biomed Central and every scientist can read your work free of charge

"BioMed Central will be the most significant development for disseminating the results of biomedical research in our lifetime. "

Sir Paul Nurse, Cancer Research UK

Your research papers will be:

- available free of charge to the entire biomedical community

- peer reviewed and published immediately upon acceptance

- cited in PubMed and archived on PubMed Central

- yours - you keep the copyright

Submit your manuscript here:

http://www.biomedcentral.com/info/publishing_adv.asp
BiolMedcentral 